REVIEW

\title{
Relaxin as a natural agent for vascular health
}

\author{
Daniele Bani \\ Department of Anatomy, Histology \\ and Forensic Medicine, Sect. Histology, \\ University of Florence, Italy
}

\begin{abstract}
Hypertension, atherothrombosis, myocardial infarction, stroke, peripheral vascular disease, and renal failure are the main manifestations of cardiovascular disease (CVD), the leading cause of death and disability in developed countries. Continuing insight into the pathophysiology of CVD can allow identification of effective therapeutic strategies to reduce the occurrence of death and/or severe disabilities. In this context, a healthy endothelium is deemed crucial to proper functioning and maintenance of anatomical integrity of the vascular system in many organs. Of note, epidemiologic studies indicate that the incidence of CVD in women is very low until menopause and increases sharply thereafter. The loss of protection against CVD in post-menopausal women has been chiefly attributed to ovarian steroid deficiency. However, besides steroids, the ovary also produces the peptide hormone relaxin (RLX), which provides potent vasoactive effects which render it the most likely candidate as the elusive physiological shield against CVD in fertile women. In particular, RLX has a specific relaxant effect on peripheral and coronary vasculature, exerted by the stimulation of endogenous nitric oxide (NO) generation by cells of the vascular wall, and can induce angiogenesis. Moreover, RLX inhibits the activation of inflammatory leukocytes and platelets, which play a key role in CVD. Experimental studies performed in vascular and blood cell in vitro and in animal models of vascular dysfunction, as well as pioneer clinical observations, have provided evidence that RLX can prevent and/or improve CVD, thus offering background to clinical trials aimed at exploring the broad therapeutic potential of human recombinant RLX as a new cardiovascular drug.
\end{abstract}

Keywords: relaxin, blood vessels, endothelial cells, vascular smooth muscle, nitric oxide, cardiovascular disease

\section{The endothelium as a key player in vascular health and disease}

Hypertension, atherothrombosis, myocardial infarction, stroke, peripheral vascular disease, and renal failure are the main manifestations of cardiovascular disease (CVD), which is the leading cause of death and disability in most developed countries, also due to the progressive increase in people's life span and expectancy (Wey 1992). Therefore, action should be taken to prevent CVD before its signs and symptoms appear or severe outcome, such as myocardial infarction or stroke, is experienced. In this context, there is a general agreement between basic and clinical scientists that a healthy endothelium is crucial to allow proper functioning and maintenance of anatomical integrity of the vascular system in many organs, including the heart, brain, kidney, lung, and placenta. Conversely, damaged or dysfunctional endothelium substantially contributes to the pathogenesis and complications of CVD (Mensah 2007; Osto et al 2007). Public health interventions for health promotion and prevention of CVD and its associated risk factors often target the endothelium, and further understanding of endothelial function can help develop innovative approaches.

Once viewed as a mere cell lining of the blood vessels serving as a barrier between the blood and the tissue extracellular matrix, the endothelium has been more recently recognized to be far more complex and functional (Figure 1). In fact, endothelial 


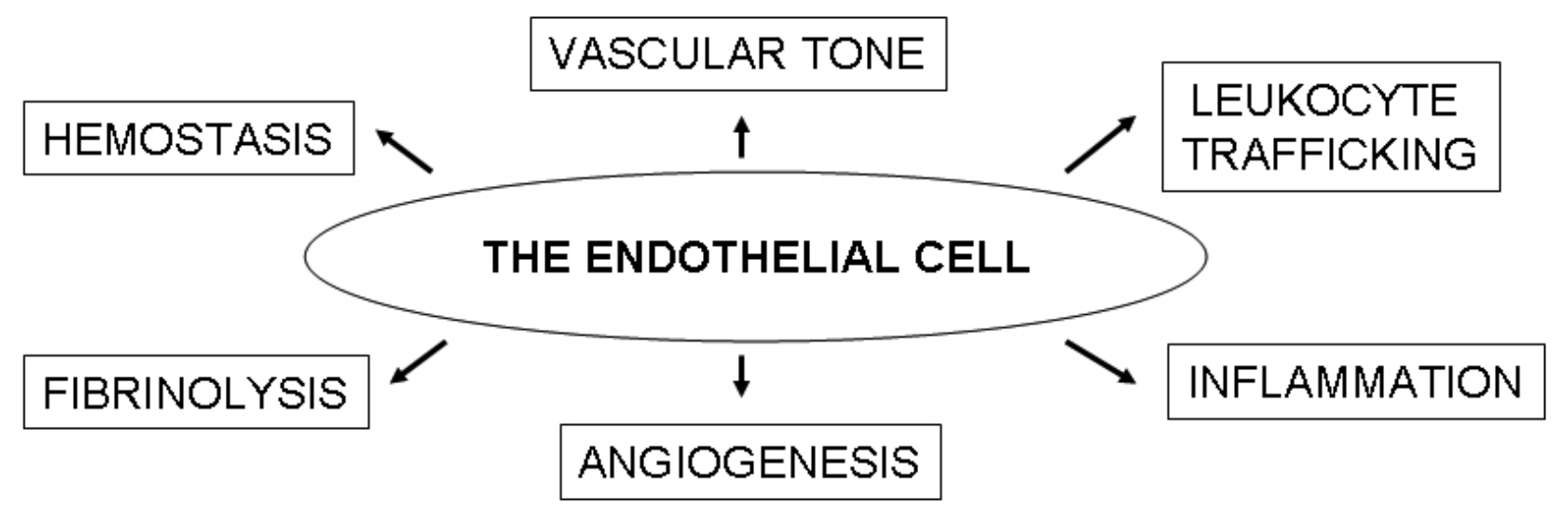

Figure I The endothelial functions.

cells play a major role in the regulation of vascular tone, hemostatic/fibrinolytic balance, angiogenesis, and leukocyte trafficking (Mensah 2007). Many of the functional properties of the endothelial cells are attributable to their unique ability to synthesize and release a variety of vasoactive mediators, including nitric oxide (NO), a gaseous free radical and key signalling molecule (Moncada et al 1991). Intact endothelial cells constitutively express NO synthase III, which continuously generates nanomolar NO amounts. In turn, endothelium-derived NO accounts for vascular smooth muscle cell relaxation and vasodilatation (Palmer et al 1987; Moncada et al 1991), angiogenic response (Ziche et al 1994), and anti-adhesive properties of the inner endothelial surface to platelets (Radomski et al 1987) and leukocytes (Kubes et al 1991) by down-regulation of endothelial cell adhesion molecules (Sluiter et al 1993). Therefore, failure of endothelial NO pathway and increased oxidative stress with loss of the protective effect of NO tips the endothelial cell balance towards a pro-atherogenic and pro-thrombotic milieu (Nedeljkovic et al 2003) and can initiate a vicious cycle of events that result in vasomotor dysfunction and vascular inflammation, which are essential components in the initiation and evolution of atherosclerosis (Napoli et al 2006). On these grounds, it is conceivable that agents that increase $\mathrm{NO}$ availability and reduce endothelial dysfunction may decrease susceptibility to CVD.

A typical paradigm of the key importance of endothelial integrity for normal vascular function is represented by the pathogenic cascade initiated and sustained by cigarette smoke (Ambrose and Barua 2004). Smoking is known to increase the incidence of peripheral and coronary artery diseases, myocardial infarction and reduced foeto-placental perfusion and foetal growth restriction (Jonas et al 1992; Price et al 1999;
Kalinka et al 2005; Zdravkovic et al 2005). Experimental and clinical investigations have provided evidence that cigarette smoke causes endothelial cell dysfunction, mainly consistent in decreased generation and bioavailability of NO, which results in defective endothelium-dependent vasodilatation and increased susceptibility to leukocyte and platelet adhesion (Barua et al 2001, 2002). Cigarette smoke is an example of the many dietary and lifestyle habits and inherited or acquired diseases predisposing to CVD, which also include obesity, hyperlipemia, diabetes, hypertension, vasculitis, and so on. In all these cases, the dysfunctional endothelium emerges as a crucial pathogenic factor and potential target for early diagnostic, preventative, and curative strategies.

\section{Gender-related differences in CVD and the role of ovarian sex hormones}

Clinical and epidemiologic studies have shown that men and women suffering from CVD differ in pathophysiology, time for onset, and prognosis upon treatment. The incidence of CVD in women is very low until menopause and increases sharply thereafter to become similar to men, but with a 10-20-year delay (Wenger et al 1993; Tunstall et al 1994; Hu et al 2000). The epidemiologic findings have been strengthened by the observation that, during fertile life, women have better endothelial function and vascular reactivity and higher NO biosynthesis than age-matched men (Forte et al 1998; Sader and Celermajer 2002). Female sex hormones have been obviously implicated in the protective effects of gender on the vasculature (Orshal and Khalil 2004; Mendelsohn and Karas 2005). Most of the existing literature 
is focused on ovarian steroids, estrogen and progesterone, which can influence vascular functions by multiple mechanisms. Estrogen and progesterone receptors are expressed by the vascular endothelium and smooth muscle (Khalil 2005): the interaction of ovarian steroids with cytosolic receptors triggers genomic effects leading to angiogenesis, endothelial NOS III up-regulation and smooth muscle growth inhibition; on the other hand, stimulation of plasma membrane receptors by these hormones initiates non-genomic effects that stimulate endothelium-dependent vasorelaxation via NO-cGMP, prostacyclin-cAMP and hyper-polarization pathways (Hayashi et al 1995; Khalil 2005; Siow et al 2007). Moreover, ovarian steroids can also influence vascular function by receptor-independent pathways, including direct antioxidant effects due to the presence of a phenolic group in their molecules (Siow et al 2007), as well as indirect effects mediated by hypothalamic-pituitary feed-back inhibition (Sader and Celermajer 2002).

On the above grounds, the loss of protection against CVD in post-menopausal women has been chiefly attributed to the deficiency of ovarian steroids. Consequently, menopausal replacement therapy has been widely advocated for primary and secondary prevention (Grodstein et al 1996). However, estrogen or progesterone have not been clearly identified as the protective agents in women. In fact, the results of estrogen/progestin replacement therapy are still controversial and under discussion (Herrington et al 2000; Rosano et al 2006). The conclusions drawn from randomized studies carried out by the Heart and Estrogen/progestin Replacement Study (HERS) Research Group (Hulley et al 1998) and the Women's Health Initiative Investigators (WHI) (Manson et al 2003), enrolling large cohorts of subjects, concur to indicate that estrogen plus progestin does not confer cardiac protection and may even increase the risk of CVD among generally healthy post-menopausal women, especially during the first year after the initiation of hormone use, most likely due to unfavorable effects of ovarian steroids upon platelet activation and coagulation (Bonnar 1987). Therefore, it has been recommended that estrogen/progestin replacement should not be prescribed for the prevention of cardiovascular disease (Manson et al 2003).

This ostensible paradox can find a logical explanation if bearing in mind that menopause causes the loss of ovarian function, which does not merely imply the cessation of estrogen and progesterone production. In fact, besides steroids, the ovary produces the peptide hormone relaxin (RLX), which also has vasoactive properties. RLX is secreted by the corpus luteum and is secreted at detectable levels in the blood of cycling and pregnant women, being absent - or at least undetectable with the current assay methods - in postmenopausal women and in men (O'Byrne et al 1978; Eddie et al 1986; Khan-Dawood et al 1989; Stewart et al 1990; Winslow et al 1992). Could RLX be the elusive natural or physiological shield against CVD in fertile women? In the following chapters, the many points in favour of this hypothesis will be summarized and reviewed.

\section{RLX, its cognate molecules, and their receptors}

RLX was discovered in 1926 by Frederick Hisaw, who observed that the injection of serum from pregnant guinea pigs or rabbits into virgin guinea pigs induced significant elongation of the interpubic ligament, attributed to stimulation of collagen turn-over (Hisaw 1926). Later on, he and his colleagues isolated from pregnant sow corpora lutea a peptide responsible for the observed relaxant effect on pubic symphisis and named it 'relaxin' (Fevold et al 1930). It is worth noting that the collagen remodeling properties of RLX first highlighted by Hisaw have been confirmed by many subsequent investigations (Unemori and Amento 1990; Unemori et al 1992, 1993, 1996; Garber et al 2001; Williams et al 2001; McDonald et al 2003; Samuel et al 2003) and remain as a hallmark of RLX and a paradigm of its specific biological effects (Sherwood 2004).

RLX has been long included in the insulin hormone superfamily because of structural homologies with insulin: both peptides have similar $6 \mathrm{kDa}$ molecular weights and are composed of A and B chains stabilized by inter- and intrachain disulfide bonds (Schwabe and Büllesbach 1994). More recently, however, it has been definitely ascertained that RLX is a member of a peptide hormone family that diverged from insulin early in vertebrate evolution; therefore, RLX has been assigned to a specific hormone family, termed the RLX peptide family, which includes three different RLXs, $\mathrm{H} 1, \mathrm{H} 2$ and H3, as well as insulin-like peptide (INSL)3, INSL4, INSL5 and INSL6 (Bathgate et al 2003; Samuel et al 2006). In humans, 3 separate RLX genes have been found and designated RLN1, RLN2 and RLN3 (Bathgate et al 2003; Samuel et al 2006). The peptide encoded by the RLN2 gene, H2 RLX, is the major circulating form and is produced mainly in the corpus luteum (Hudson et al 1984). Circulating RLX accounts for most of the known biological effects of the hormone in humans and experimental animals. RLX acts on the female reproductive system as well as on non-reproductive targets, including the cardiovascular system and the connective tissue (Bani 1997; Conrad and 
Novak 2004; Sherwood 2004; Dschietzig et al 2006; Samuel et al 2006; Nistri et al 2007).

RLX is the ligand for two leucine-rich repeat-containing G-protein coupled receptors (LGRs), LGR7 and LGR8 (Hsu et al 2002), now classified as relaxin family peptide receptors 1 and 2 (RXFP1 and RXFP2), respectively (Bathgate et al 2006). RXFP1 is the main and most specific H2 RLX receptor, but it is also able to bind $\mathrm{H} 1$ and $\mathrm{H} 3 \mathrm{RLX}$, although with less affinity. On the other hand, RXFP2 chiefly binds INSL 3 and also H1 and H2 RLX, but with less affinity (Hsu et al 2002; Sudo et al 2003). These receptors have been found on most if not all RLX target tissues and cells, and are abundantly expressed in the reproductive, nervous, renal and cardiovascular systems (Hsu et al 2002). More recently, other $\mathrm{G}$ protein-coupled receptors for peptides of the relaxin family have been discovered and termed RXFP3 (formerly GPCR135) and RXFP4 (formerly GPCR142) (Bathgate et al 2006). RXFP3 binds H3 RLX with high affinity (Liu et al 2003a) while RXFP4 binds H3 RLX (Liu et al 2003b) and also INSL5 (Liu et al 2005). Moreover, RLX has been reported to act as an agonist for cytoplasmic glucocorticoid receptors, thereby exerting possible cortisol-like effects (Dschietzig et al 2004). Binding of RLX to its surface receptor results in the activation of multiple intracellular response pathways, which include cAMP and NO as second messengers (Hsu et al 2002; Nistri and Bani 2003). In particular, the observation that RLX can up-regulate NO biosynthesis in several of its targets underscores its potential as cardiovascular hormone, $\mathrm{NO}$ being a key regulator of vascular function (Moncada et al 1991; Nathan 1992).

\section{RLX and the vascular system}

Peculiarly, the first reports on the ability of RLX to influence blood vessels came from clinical rather than basic research. During the late 1950s and early 1960s, the Warner-Chilcott Laboratories provided an impure preparation of porcine RLX, commercially available as Releasin, and supported studies in humans that examined the use of relaxin as a therapeutic agent for scleroderma, cervical ripening and premature labor, based on its collagen-remodeling properties. Releasin, injected intramuscularly to patients suffering for peripheral vascular diseases and Raynaud's syndrome, caused a dramatic, albeit transient, amelioration of symptoms and signs of ischemia (Casten and Boucek 1958; Casten et al 1960). These effects were attributed to increased compliance of the blood vessels due to loosening of their adventitial extracellular matrix. However, Casten and colleagues also reported that, in some patients who also suffered for ischemic heart disease, Releasin treatment led to the reduction of the daily glyceryl trinitrate requirements. Retrospectively, this important observation clearly suggests that RLX does have a direct, dilatory effect on peripheral and coronary vasculature. Subsequent studies in monkeys by the Hisaw's group described an enlargement of endometrial arterioles and capillaries (Dallenbach-Hellweg et al 1966) and provided first evidence for an angiogenic effect of RLX on endothelial cells of the endometrial blood vessels (Hisaw 1967). Definite recognition of the blood vessels as specific RLX targets came from the identification of RLX binding sites/receptors on vascular cells in reproductive and non-reproductive organs (Min and Sherwood 1996; Kohsaka et al 1998; Hsu et al 2002).

Vasodilatation may be regarded as an additional, specific hallmark of RLX, as it has been observed in many target organs and tissues, regardless of gender. RLX-induced vasodilatation mainly involves the distal segments of the vascular tree, namely arterioles provided with a smooth muscle coat as well as capillaries and post-capillary venules, which lack smooth muscle in their wall. Of note, RLX promotes vasodilatation in reproductive organs, such as the uterus (Vasilenko et al 1986; Bani G et al 1995) and the mammary gland (Bani et al 1988), as well as in non-reproductive targets, including mesocaecum (Bigazzi et al 1986), kidney (Danielson et al 1999, 2000; Novak et al 2001), liver (Bani et al 2001), lung (Bani et al 1997), and heart (Bani Sacchi et al 1995; Masini et al 1997). Vasodilatation appears as a physiologic effect of RLX since it is fully manifest at hormone concentrations which are in the nanomolar range, similar to the RLX blood levels of normal human pregnancy (O'Byrne et al 1978; Eddie et al 1986). RLX is extremely potent as a vasorelaxant: in the isolated, perfused rat and guinea pig heart, the dose-dependent increase in coronary flow induced by RLX is significantly higher than that obtained with similar doses of typical vasodilatatory agents such as acetylcholine or sodium nitroprusside (Bani Sacchi et al 1995); in the mesocaecum, RLX counteracted similar concentrations of norepinephine (Bigazzi et al 1986). Vasodilatation also emerges as a primary effect of RLX and is not secondary to tissue growth stimulation, as it could be appreciated even in the absence of any growth response.

Of note, the vasodilatatory effects of RLX are most prominent in vasoconstricted blood vessels, rather than in normal blood vessels, suggesting that this hormone could act as a natural regulator of vascular tone and a shield against the derangements of vascular reactivity. In the rat kidney, RLX reduces the myogenic activity of small arteries and blunts the vasoconstrictive response to angiotensin II, in both genders 
(Danielson et al 1999, 2000; Novak et al 2001). In a rat model of renal artery ligation, RLX counteracts the increase in systemic blood pressure due to activation of the reninangiotensin system (Garber et al 2003). In spontaneously hypertensive rats (SHR), but not normotensive rats, RLX reduces blood pressure and blunts the response of mesenteric vessels to vasoconstrictors (St Louis et al 1985).

Besides vasodilatation, RLX can also induce angiogenesis in some target organs, as suggested by the pioneer findings by Hisaw (1967), using partially purified RLX. In human endometrial cells in vitro, RLX induces the production of potent angiogenic molecules such as basic fibroblast growth factor (bFGF) and vascular endothelial growth factor (VEGF) (Unemori et al 1999). In a rat model of chronic myocardial infarction, systemic infusion of RLX potentates bFGF mRNA expression in the peri-infarct region by both cardiomyocytes and fibroblasts (Lewis et al 2001). Similarly, in a swine model of post-infarcted heart, locally produced RLX by RLN2 gene-transfected myoblasts grafted into the post-ischemic myocardium, causes a significant increase in microvessel density and over-expression of VEGF mRNA by the host cardiac cells (Formigli et al 2007). Thus, RLX, by promoting vasodilation and, at least in some conditions, angiogenesis could influence the perfusion of many target organs.

Sound experimental evidence exists that the vasoactive action of RLX can be chiefly ascribed to the prompt synthesis and release of the potent vasodilator NO (Moncada et al 1991; Nathan 1992) by blood vessel cells. In vitro studies have shown that addition of RLX to the culture medium of endothelial cells from rat coronaries and human umbilical vein and of bovine vascular smooth muscle cells causes a dose-dependent increase in the production of NO and in the intracellular levels of cGMP (Bani et al 1998a; Failli et al 2001; Quattrone et al 2004), the mediator of the cell response to NO (Ignarro 1991). This is accompanied by a concurrent decrease in cytosolic $\mathrm{Ca}^{2+}$ concentration and by morphological changes in cell shape and cytoskeletal contractile microfilaments consistent with cell relaxation (Bani et al 1998a). RLX activates endogenous NO biosynthesis by increasing the expression and activity of inducible NO synthase (NOS II) in both cell types (Bani et al 1998a; Failli et al 2001; Quattrone et al 2004). In keeping with these findings, RLX has been found to up-regulate endothelin type-B $\left(\mathrm{ET}_{\mathrm{B}}\right)$ receptors and the release of $\mathrm{NO}$ on the renal vascular endothelium in the rat in vivo (Conrad et al 1999). Based on the current literature, there are multiple pathways by which the G protein-coupled RLX receptors can stimulate
NO generation (Nistri and Bani 2003). In endothelial cells, constitutive NO synthase (NOS III) activity is stimulated by vasoactive agonists and hormones, such as acetylcholine, bradykinin and estrogens, which also act by specific membrane-associated G protein-coupled receptors (Liu et al 1995; Vanhoutte 1997; Wyckoff et al 2001). The classical signaling pathway involves $G$ protein $\beta \gamma$ subunits that, through phosphoinositide 3-kinase (PI3-K), switch on protein kinase B (Akt), which in turn activates NOS III by phosphorylation at Ser-1179 (Igarashi and Michel 2001). Another mechanism, which may either coexist in the same cell or be alternatively operating in different cell types, could involve cAMP and the inducible NOS II isoform. In rat vascular smooth muscle cells, G protein-coupled receptor-activated adenylate cyclase and the consequent rise in cAMP upregulates protein kinase A (PKA) activity (Kim et al 2002). In turn, PKA is able to phosphorylate and inactivate $\mathrm{IkB}-\alpha$, the inhibitor subunit of the transcription factor NF- $\kappa \mathrm{B}$, thus allowing NF- $\kappa \mathrm{B}$ to translocate into the nucleus and to promote the expression of NOS II (Grimm and Baeuerle 1993). This latter mechanism may be also operating in the noted RLX vascular target cells, in which induction of NOS II expression and high-output, sustained NO generation have been observed (Bani et al 1998a; Failli et al 2001). It has been also suggested that RLX may indirectly activate the NO pathway through the stimulation of extracellular matrix-remodeling. In fact, RLX-induced collagenase activation could convert big endothelin (ET)-1 into bioactive $\mathrm{ET}_{1-32}$, which in turn binds to and activates $\mathrm{ET}_{\mathrm{B}}$ receptors, thereby inducing NOS III activation and NO release (Conrad and Novak 2004).

Whichever intracellular mechanism is involved in the upregulation of endogenous NO generation by vascular cells, RLX clearly emerges from the above studies as a major vasoactive hormone and potential drug able to influence vascular tone and, consequently, organ and tissue perfusion.

\section{Relaxin and vascular dysfunction}

As summarized in the introduction, endothelial dysfunction is a crucial event in the initiation and evolution of atherosclerosis and CVD (Napoli et al 2006). The damaged endothelium becomes unable to generate vasoactive autacoids, chiefly NO and prostaglandins, and loses its physiological function to control vasomotion and blood cell adhesion (Nedeljkovic et al 2003). Thence, vasospasm and ischemia on one hand, and recruitment and activation of inflammatory leukocytes and platelets on the other hand, can occur and cause overall vascular and organ injury and degeneration. Multiple lines of evidence, both experimental and clinical, converge to suggest 
that RLX may beneficially interfere with this pathogenic cascade (Figure 2).

Our previous in vitro studies on vascular endothelial cells suggest that RLX could sustain endogenous NO generation by an alternate pathway to the constitutive NOS III, ie, by the expression of inducible NOS II (Failli et al 2001; Quattrone et al 2004). This mechanism may likely attain biological and pharmacological relevance when RLX is administered to functional endothelium to prevent the adverse effects of the different causes of endothelial failure, but it cannot be ruled out that it could also be operating on early damaged endothelium, thereby reverting initial NO failure and interrupting the vicious cycle that would further worsen endothelial injury and dysfunction. Sustained endothelial NO generation by RLX can counteract vasoconstriction as well as leukocyte adhesion and vascular inflammation. We have recently demonstrated that RLX can reduce the endothelial adhesiveness to neutrophils in pro-inflammatory conditions in vitro by down-regulating early- and late-phase endothelial cell adhesion molecules (Nistri et al 2003). Moreover, besides the endothelium, RLX can also influence the other aspect of vascular inflammation, ie, the leukocytes. In fact, RLX has been shown to strongly inhibit the activation of neutrophils challenged in vitro with inflammatory mediators, by reducing oxidative burst, reactive oxygen species (ROS) generation and chemotaxis (Masini et al 2004). Finally, RLX has been reported to reduce markedly, and in a dose-dependent fashion, the aggregation of platelets (Bani et al 1995, 2007), which represents another pathogenic pillar of atherosclerosis. These multiple anti-inflammatory, anti-thrombotic effects of RLX rely on the stimulation of endogenous NO generation, but other concurrent mechanisms are likely to be involved. As cited in a earlier, it has been recently demonstrated that RLX may act as a glucocorticoid receptor agonist by a RXFP receptor-independent pathway, thereby mimicking some of the anti-inflammatory effects of cortisol (Dschietzig et al 2004).

The recent literature reports several experimental studies on animal models of disease whose results validate the above theoretical concept that RLX may be beneficial in

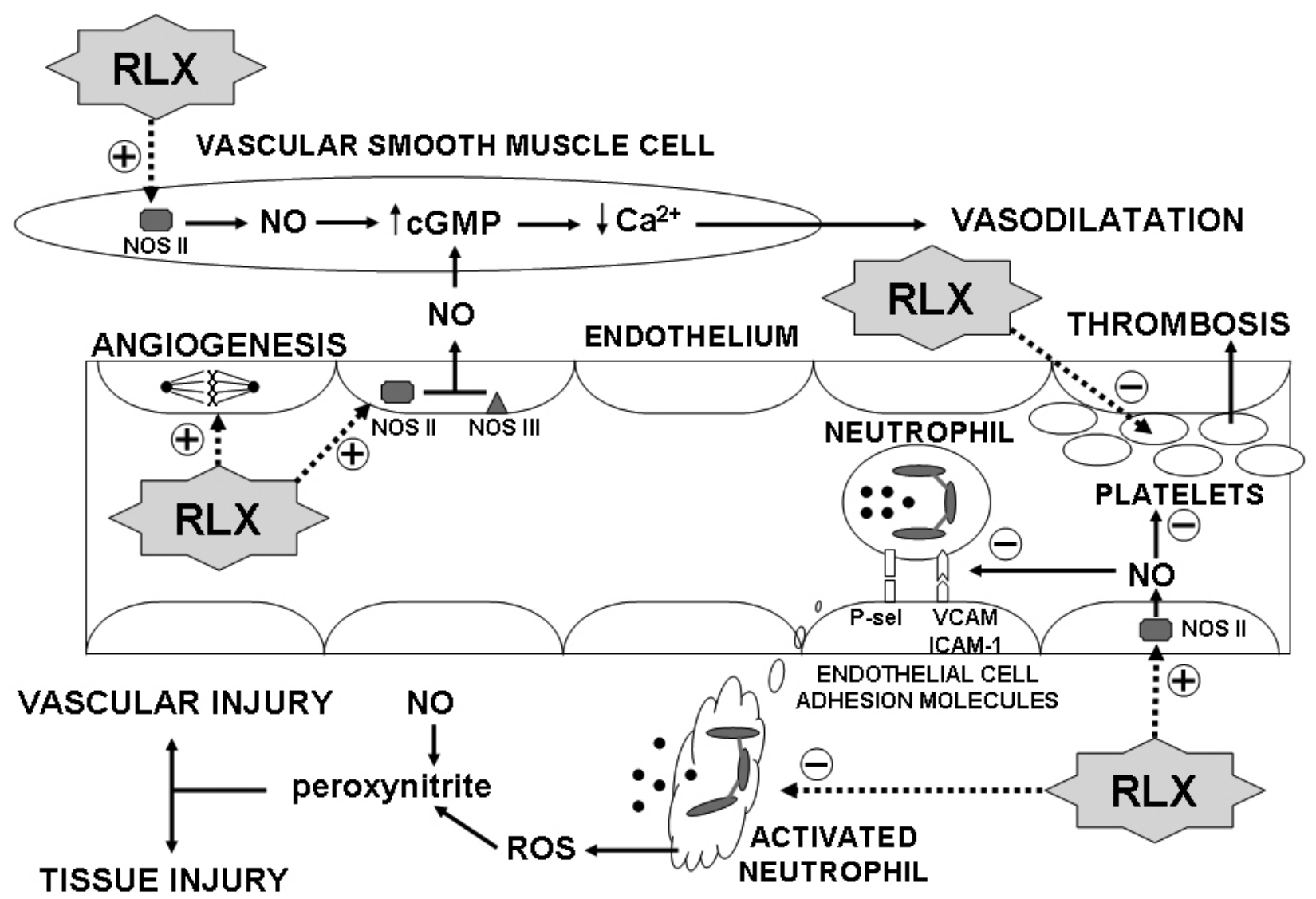

Figure 2 Schematic diagram highlighting the role of the endothelium in the pathophysiology of vascular dysfunction and the targets for RLX action, which include i) up-regulation of NOS II and endogenous NO production in endothelial and vascular smooth muscle cells, leading to vascular relaxation; reduced expression of endothelial cell adhesion molecules; reduced adhesion and activation of neutrophils, leading to diminished oxidative stress and tissue injury; reduced platelet activation; angiogenesis. 
CVD. In particular, we have provided evidence that RLX, administered to isolated, perfused guinea pig hearts or to intact rats in vivo, protects the heart against myocardial injury caused by ischemia and reperfusion (IR) (Masini et al 1997; Bani et al 1998b). During IR, there is a primary damage of the coronary endothelium leading to impaired production of NO. This triggers a cascade of events, such as vasoconstriction, leukocyte and platelet recruitment, ROS generation and oxidative stress, mast cell activation and histamine release and so on, which result in myocardial contractile dysfunction and, eventually, irreversible myocardial injury (Lefer et al 1991). RLX, given preventatively before ischemia, caused a significant reduction of the myocardial tissue area damaged by post-ischemic reperfusion, as well as reducing the occurrence of severe ventricular arrhythmias. RLX also reduced myocardial neutrophil accumulation, platelet and mast cell activation, ROS-induced tissue injury and histopathological signs of irreversible cardiomyocyte and endothelial injury (Masini et al 1997; Bani et al 1998b). The cardioprotective action of RLX can go beyond the prevention of IR-induced myocardial damage and may find a therapeutic application in myocardial infarction. Recently, we used a swine model of cardiac IR in which RLX was administered at reperfusion to reproduce an adjunctive medical therapy to primary coronary angioplasty in patients with acute myocardial infarction. In these studies, RLX, given at reperfusion upon a 30-min ischemia at doses yielding physiological or juxta-physiological plasma concentrations, caused a marked, dose-related reduction of the main serum markers of myocardial damage as well as of the metabolic and histopathological parameters of cardiomyocyte injury and apoptosis and myocardial inflammation. These effects of RLX resulted in increased myocardial salvage and improved ventricular performance (Bani et al 2005; Perna et al 2005). These findings provide support to the above concept that RLX may be also effective on the endothelium damaged by ischemia, likely counteracting the NO failure and preventing severe endothelial injury and dysfunction. Our pioneering studies on RLX-induced protection in cardiac IR have been confirmed and extended by a recent study on rats with isoproterenol-induced cardiac ischemia, in which the assayed parameters of myocardial damage and dysfunction improved markedly upon treatment with exogenous RLX (Zhang et al 2005). Of note, in this study, the injured heart also appears to up-regulate the production and release of endogenous RLX, providing support to the view that RLX is a cardiac hormone (Taylor and Clark 1994) and may have paracrine effects against cardiac ischemic injury and dysfunction (Dschietzig et al 2001).
As occurs in the heart, RLX has been shown to protect against IR-induced injury in other organs, such as the liver (Boehnert et al 2005), the small bowel (Masini et al 2006), the pancreas (Cosen-Binker et al 2006) and the brain (Wilson et al 2006). In all these studies, direct or indirect evidence is provided that the protection afforded by RLX relies on its effects on the endothelium and often involve endogenous NO generation.

From a clinical perspective, evidence for the efficacy of RLX as a vascular protector emerges from the early studies of Casten and colleagues (1960), who successfully used RLX to treat patients with peripheral vascular diseases and obtained impressive amelioration of peripheral arteriopathy and ischemic ulcers. Moreover, in subjects also suffering from ischemic heart disease, RLX reduced the need for daily nitrovasodilatator therapy. Possible criticisms raised by the use of an impure RLX preparation are overridden by a more recent observation that clinical grade human recombinant RLX, given as merciful therapy to a patient with severe idiopathic occlusive peripheral arterial disease of the lower limbs, caused a marked, long-lasting amelioration of both subjective symptoms and objective clinical and instrumental signs (Bani and Bigazzi 2005). This clinical experience, albeit limited to a single patient, confirms the findings of Casten and colleagues and gives further momentum to future clinical studies in this direction.

Another clinical issue highlighting the vasoprotective role of RLX and its possible therapeutical use is pre-eclampsia, a disease of late pregnancy characterized by de novo occurrence of hypertension and proteinuria and by histopathological signs of peripheral and placental endothelial injury. Its occurrence is the leading cause of pre-term delivery and fetal growth restriction and predisposes both the offspring and the mother to subsequent cardiovascular risk (Smith et al 2001). Recently, compelling evidence has been brought forth suggesting a major role for soluble growth factor receptor fms-like tyrosine kinase 1, asymmetric dimethyl arginine and autoantibodies in the pathophysiology of pre-eclampsia. These molecules are present at abnormally high levels in the blood of pre-eclamptic women and lead to inactivation of circulating pro-angiogenic factors, inhibition of endothelial NO biosynthesis and stimulation of angiotensin receptors, thereby causing pre-eclampsia (Davison et al 2004). As RLX can increase renal vasodilation and hyperfiltration, reduce myogenic reactivity of small renal arteries through activation of the endothelin $\mathrm{B}$ receptorNO pathway (Danielson et al 1999, 2000; Novak et al 2001) and stimulate endothelial NO generation (Bani et al 1998a; Failli et al 2001; Quattrone et al 2004), it appears 
the perfect candidate to counteract the pathogenic events of pre-eclampsia. To test this hypothesis a randomized, double-blind, placebo controlled clinical trial is currently in progress in the United States (www.clinicaltrials.gov; No NCT00333307) sponsored by BAS Medical, owner of the patent for human recombinant RLX. Hopefully, this study could provide exciting new suggestions for the possible clinical use of RLX in pre-eclamptic patients.

\section{Concluding remarks}

The studies that I have briefly summarized in the above paragraphs offer clear-cut evidence that RLX has specific effects on the vascular and blood cells which may help counteract the different pathogenic aspects of CVD. Many clues also suggest that RLX could be the elusive ovarian hormone involved in the protection of fertile women from CVD. The experimental studies, especially those performed in animal models of vascular dysfunction, provide background to current and future clinical trials aimed at exploring the broad therapeutic potential of human recombinant RLX as a new cardiovascular drug.

\section{References}

Ambrose JA, Barua RS. 2004. The pathophysiology of cigarette smoking and cardiovascular disease. $J$ Am Coll Cardiol, 43:1731-7.

Bani D, Bigazzi M, Masini E, et al. 1995. Relaxin depresses platelet aggregation: in vitro studies on isolated human and rabbit platelets. Lab Invest, 73:709-16.

Bani D. 1997. Relaxin, a pleiotropic hormone. Gen Pharmacol, 28:13-22.

Bani D, Ballati L, Masini E, et al. 1997. Relaxin counteracts asthma-like reaction induced by inhaled antigen in sensitized guinea pigs. Endocrinology, 138:1909-15.

Bani D, Failli P, Bello MG, et al. 1998a. Relaxin activates the L-arginine-nitric oxide pathway in vascular smooth muscle cells in culture. Hypertension, 31:1240-7.

Bani D, Masini E, Bello MG, et al. 1998b. Relaxin protects against myocardial injury caused by ischemia and reperfusion in rat heart. Am J Pathol, 152:1367-76.

Bani D, Nistri S, Quattrone S, et al. 2001. The vasorelaxant hormone relaxin induces changes in liver sinusoid microcirculation: a morphologic study in the rat. $J$ Endocrinol, 171:541-9.

Bani D, Bigazzi M. 2005. Clinical aspects and therapeutic perspectives of relaxin. Curr Med Chem - Immunology, Endocrine and Metabolic Agents (CMC-IEMA) 5:403-10.

Bani D, Nistri S, Bani Sacchi T, et al. 2005. Basic progress and future therapeutic perspectives of relaxin in ischemic heart disease. Ann NY Acad Sci, 1041:423-30.

Bani D, Nistri S, Cinci L, et al. 2007. A novel, simple bioactivity assay for relaxin based on inhibition of platelet aggregation. Regul Peptides, in press.

Bani G, Bani Sacchi T, Bigazzi M, et al. 1988. Effects of relaxin on the microvasculature of mouse mammary gland. Histol Histopath, 3:337-43.

Bani G, Maurizi M, Bigazzi M, et al. 1995. Effects of relaxin on the endometrial stroma. Studies in mice. Biol Reprod, 53:253-62.

Bani Sacchi T, Bigazzi M, Bani D, et al. 1995. Relaxin-induced increased coronary flow through stimulation of nitric oxide production. Brit J Pharmacol, 116:1589-94.
Barua RS, Ambrose JA, Eales-Reynolds LJ, et al. 2001. Dysfunctional endothelial nitric oxide biosynthesis in healthy smokers with impaired endothelium-dependent vasodilatation. Circulation, 104:1905-10.

Barua RS, Ambrose JA, Saha DC, et al. 2002. Smoking is associated with altered endothelial-derived fibrinolytic and antithrombotic factors: an in vitro demonstration. Circulation, 106:905-8.

Bathgate RA, Samuel CS, Burazin TC, et al. 2003. Relaxin: new peptides, receptors and novel actions. Trends Endocrinol Metab, 14:207-13.

Bathgate RA, Ivell R, Sanborn BM, et al. 2006. International Union of Pharmacology LVII: Recommendations for the nomenclature of receptors for relaxin family peptides. Pharmacol Rev, 58:7-31.

Bigazzi M, Del Mese A, Petrucci F, et al. 1986. The local administration of relaxin induces changes in the microcirculation of the rat mesocaecum. Acta Endocrinol, 112:296-9.

Boehnert MU, Hilbig H, Armbruster FP. 2005. Relaxin as an additional protective substance in preserving and reperfusion solution for liver transplantation, shown in a model of isolated perfused rat liver. Ann $N$ Y Acad Sci, 1041:434-40.

Bonnar J. 1987. Coagulation effects of oral contraception. Am J Obstet Gynecol, 157:1042-8.

Casten GG, Boucek RJ. 1958. Use of relaxin in the treatment of scleroderma. JAMA, 166:319-24.

Casten GG, Gilmore HR, Houghton FE, et al. 1960. A new approach to the management of obliterative peripheral arterial disease. Angiology, 11:408-14.

Conrad KP, Gandley RE, Ogawa T, et al. 1999. Endothelin mediates renal vasodilation and hyperfiltration during pregnancy in chronically instrumented conscious rats. Am J Physiol Renal Physiol, 276:F767-76.

Conrad KP, Novak J. 2004. Emerging role of relaxin in renal and cardiovascular function. Am J Physiol Regul Integr Comp Physiol, 287:250-61.

Cosen-Binker LI, Binker MG, Cosen R, et al. 2006. Relaxin prevents the development of severe acute pancreatitis. World J Gastroenterol, 12:1558-68.

Dallenbach-Hellweg G, Dawson AB, Hisaw FL. 1966. The effect of relaxin on the endometrium of monkeys-histological and histochemical studies. Am J Anat, 119:61-78.

Danielson LA, Sherwood OD, Conrad KP. 1999. Relaxin is a potent renal vasodilator in conscious rats. $J$ Clin Invest, 103:525-33.

Danielson LA, Kercher LJ, Conrad KP. 2000. Impact of gender and endothelin on renal vasodilation and hyperfiltration induced by relaxin in conscious rats. Am J Physiol Regul Integr Comp Physiol, 279: R1298-304.

Davison JM, Homuth V, Jeyabalan A, et al. 2004. New aspects in the pathophysiology of preeclampsia. J Am Soc Nephrol, 15:2440-8.

Dschietzig T, Ritcher C, Bartsch C, et al. 2001. The pregnancy hormone relaxin is a player in human heart failure. FASEB $J, 165: 2187-95$.

Dschietzig T, Bartsch C, Stangl V, et al. 2004. Identification of the pregnancy hormone relaxin as glucocorticoid receptor agonist. FASEB J, 13:1536-8.

Dschietzig T, Bartsch C, Baumann G, et al. 2006. Relaxin - a pleiotropic hormone and its emerging role for experimental and clinical therapeutics. Pharm Ther, 112:38-56.

Eddie LW, Bell RJ, Lester A, et al. 1986. Radioimmunoassay of relaxin in pregnancy with an analogue of human relaxin. Lancet, 8494:1344-6.

Failli P, Nistri S, Quattrone S, et al. 2001. Relaxin up-regulates inducible nitric oxide synthase expression and nitric oxide generation in rat coronary endothelial cells. FASEB J, 16:252-4.

Fevold HL, Hisaw FL, Meyer RK. 1930. The relaxative hormone of the corpus luteum. Its purification and concentration. $\mathrm{J} \mathrm{Am} \mathrm{Chem} \mathrm{Soc,}$ 52:3340-8.

Formigli L, Perna AM, Meacci E, et al. 2007. Paracrine effects of transplanted myoblasts and relaxin on post-infarction heart remodeling. J Cell Mol Med, 11:1101-4. 
Forte P, Kneale BJ, Milne E, et al. 1998. Evidence for a difference in nitric oxide biosynthesis between healthy women and men. Hypertension, 32:730-4.

Garber SL, Mirochnik Y, Brecklin CS, et al. 2001. Relaxin decreases renal interstitial fibrosis and slows progression of renal disease. Kidney Int, 59:876-82.

Garber SL, Mirochnik Y, Brecklin C, et al. 2003. Effect of relaxin in two models of renal mass reduction. Am J Nephrol, 23:8-12.

Grimm S, Baeuerle PA. 1993. Review article: the inducible transcription factor $\mathrm{NF}-\mathrm{KB}$ : structure-function relationship of its protein subunits. Biochem J, 290:297-308.

Grodstein F, Stampfer MJ, Manson JE, et al. 1996. Postmenopausal estrogen and progestin use and the risk of cardiovascular disease. $N$ Engl $J$ Med, 335:453-61.

Hayashi S, Yamada K, Esaki T et al. 1995. estrogen increases endothelial nitric oxide by a receptor-mediated system. Biochim Biophys Res Commun, 214:847-55.

Herrington DM, Reboussin DM, Brosnihan KB, et al. 2000. Effects of estrogen replacement on the progression of coronary-artery atherosclerosis. N Engl J Med, 343:522-9.

Hisaw FL. 1926. Experimental relaxation of the pubic ligament of the guinea pig. Proc Soc Exp Biol Med, 23:661-3.

Hisaw FL, Hisaw FL Jr, Dawson AB. 1967. Effect of relaxin on the endothelium of endometrial blood vessels in monkey (Macaca mulatta). Endocrinology, 81:375-85.

Hsu SY, Nakabayashi K, Nishi S, et al. 2002. Activation of orphan receptors by the hormone relaxin. Science, 295:671-4.

Hu FB, Stampfer MJ, Manson JE, et al. 2000. Trends in the incidence of coronary heart disease and changes in diet and lifestyle in women. N Engl J Med, 343:530-7.

Hudson P, John M, Crawford R, et al. 1984. Relaxin gene expression in human ovaries and the predicted structure of a human preprorelaxin by analysis of cDNA clones. EMBO J, 3:2333-9.

Hulley S, Grady D, Bush T, et al. 1998. Randomized trial of estrogen plus progestin for secondary prevention of coronary heart disease in postmenopausal women. Heart and Estrogen/progestin Replacement Study (HERS) Research Group. JAMA, 280:605-13.

Igarashi J, Michel T. 2001. Sphingosine 1-phosphate and isoform-specific activation of phosphoinositide 3-kinase beta. Evidence for divergence and convergence of receptor-regulated endothelial nitric-oxide synthase signaling pathways. J Biol Chem, 276:36281-8.

Ignarro LJ. 1991. Signal transduction mechanisms involving nitric oxide. Biochem Pharmacol, 41:485-90.

Jonas MA, Oates JA, Ockene JK, et al. 1992. Statement on smoking and cardiovascular disease for health care professionals. American Heart Association. Circulation, 86:1664-9.

Kalinka J, Hanke W, Sobala W. 2005. Impact of prenatal tobacco smoke exposure, as measured by midgestation serum cotinine levels, on fetal biometry and umbilical flow velocity waveforms. Am J Perinatol, 22:41-7.

Khalil RA. 2005. Sex hormones as potential modulators of vascular function in hypertension. Hypertension, 46:249-54.

Khan-Dawood FS, Goldsmith LT, Weiss G, et al. 1989. Human corpus luteum secretion of relaxin, oxytocin and progesterone. J Clin Endocrinol Metab, 68:627-31.

Kim NY, Pae HO, Kim YC, et al. 2002. Pentoxifylline potentiates nitric oxide production in interleukin-1beta-stimulated vascular smooth muscle cells through cyclic AMP-dependent protein kinase A pathway. Gen Pharmacol, 35:205-11.

Kohsaka T, Min G, Lukas G, et al. 1998. Identification of specific relaxinbinding cells in the human female. Biol Reprod, 59:991-9.

Kubes P, Suzuki M, Granger DN. 1991. Nitric oxide: an endogenous modulator of leukocyte adhesion. Proc Natl Acad Sci USA, 88:4651-5.

Lefer AM, Tsao PS, Lefer DJ, et al. 1991. Role of endothelial dysfunction in the pathogenesis of reperfusion injury after myocardial ischemia. FASEB J, 5:2029-34.
Lewis M, Deshpande U, Guzman L, et al. 2001. Systemic relaxin administration stimulates angiogenic cytokine expression and vessel formation in a rat myocardial infarct model. In: Tregear GW, Ivell R, Bathgate RA, Wade DJ eds. Relaxin 2001: Proceedings of the 3rd international conference on relaxin and related peptides. Dordrecht, The Netherlands: Kluwer, pp 159-67.

Liu J, Conklin BR, Blin N, et al. 1995. Identification of a receptor/G-protein contact site critical for signaling specificity and G-protein activation. Proc Natl Acad Sci USA, 92:11642-6.

Liu C, Chen J, Sutton S, et al. 2003a. Identification of relaxin-3/INSL7 as a ligand for GPCR142. J Biol Chem, 278:50765-70.

Liu C, Eriste E, Sutton S, et al. 2003b. Identification of relaxin-3/INSL7 as an endogenous ligand for the orphan G-protein-coupled receptor GPCR135. J Biol Chem, 278:50754-64.

Liu C, Kuei C, Sutton S, et al. 2005. INSL5 is a high affinity specific agonist for GPCR142 (GPR100). J Biol Chem, 280:292-300.

Manson JE, Hsia J, Johnson KC, et al. 2003. Women's Health Initiative Investigators. Estrogen plus progestin and the risk of coronary heart disease. N Engl J Med, 349:523-34.

Masini E, Bani D, Bello MG, et al. 1997. Relaxin counteracts myocardial damage induced by ischemia-reperfusion in isolated guinea pig hearts: evidence for an involvement of nitric oxide. Endocrinology, 138:4713-20

Masini E, Nistri S, Vannacci A, et al. 2004. Relaxin inhibits the activation of human neutrophils: involvement of the nitric oxide pathway. Endocrinology, 145:1106-12.

Masini E, Cuzzocrea S, Mazzon E, et al. 2006. Protective effects of relaxin in ischemia/reperfusion-induced intestinal injury due to splanchnic artery occlusion. Brit J Pharmacol, 148:1124-32.

McDonald GA, Sarkar P, Rennke H, et al. 2003. Relaxin increases ubiquitin-dependent degradation of fibronectin in vitro and ameliorates renal fibrosis in vivo. Am J Physiol Renal Physiol, 285:F59-F67.

Mendelsohn ME, Karas RH. 2005. Molecular and cellular basis of cardiovascular gender differences. Science, 308:1583-7.

Mensah GA. 2007. Healthy endothelium: the scientific basis for cardiovascular health promotion and chronic disease prevention. Vasc Pharmacol, 46:310-4.

Min G, Sherwood OD. 1996. Identification of specific relaxin-binding sites in the cervix, mammary glands, nipples, small intestine and skin of pregnant pigs. Biol Reprod, 55:1243-52.

Moncada S, Palmer RMJ, Higgs EA. 1991. Nitric oxide physiology, pathophysiology, and pharmacology. Pharmacol Rev, 43:109-42.

Napoli C, de Nigris F, Williams-Ignarro S, et al. 2006. Nitric oxide and atherosclerosis: an update. Nitric Oxide, 15:265-79.

Nathan C. 1992. Nitric oxide as a secretory product of mammalian cells. FASEB J, 6:3051-64.

Nedeljkovic ZS, Gokce N, Loscalzo J. 2003. Mechanisms of oxidative stress and vascular dysfunction. Postgrad Med, J 79:195-9.

Nistri S, Bani D. 2003. Relaxin receptors and nitric oxide synthases. Search for the missing link. Reprod Biol Endocrinol, 1:5.

Nistri S, Chiappini L, Sassoli C, et al. 2003. Relaxin inhibits lipopolysaccharide-induced adhesion of neutrophils to coronary endothelial cells by a nitric oxide-mediated mechanism. FASEB J, 17:2109-11.

Nistri S, Bigazzi M, Bani D. 2007. Relaxin as a cardiovascular hormone. Physiology, pathophysiology and therapeutic promises. Cardiovasc Hematol Agents Med Chem (CHA-MC), 5:101-8.

Novak J, Danielson LA, Kerchner LJ, et al. 2001. Relaxin is essential for renal vasodilation during pregnancy in conscious rats. J Clin Invest, 107:1469-75.

O’Byrne EM, Carriere BT, Sorensen L, et al. 1978. Plasma immunoreactive relaxin levels in pregnant and nonpregnant women. J Clin Endocrinol Metab, 47:1106-10.

Orshal JM, Khalil RA. 2004. Gender, sex hormones, and vascular tone. $A m$ J Physiol Regul Integr Comp Physiol, 286:R233-49.

Osto E, Coppolino G, Volpe M, et al. 2007. Restoring the dysfunctional endothelium. Curr Pharm Des, 13:1053-68. 
Palmer RMJ, Ferrige A, Moncada S. 1987. Nitric oxide release accounts for the biological activity of endothelium-derived relaxing factor. Nature, 327:524-6.

Perna AM, Masini E, Nistri S, et al. 2005. Novel drug development opportunity for relaxin in acute myocardial infarction. evidences from a swine model. FASEB J, 19:1525-7

Price JF, Mowbray PI, Lee AJ, et al. 1999. Relationship between smoking and cardiovascular risk factors in the development of peripheral arterial disease and coronary artery disease: Edinburgh Artery Study. Eur Heart J, 20:344-53.

Quattrone S, Chiappini L, Scapagnini G, et al. 2004. Relaxin potentiates the expression of inducible nitric oxide synthase by endothelial cells from human umbilical vein in in vitro culture. Mol Hum Reprod, 10:325-30.

Radomski MV, Palmer RMJ, Moncada S. 1987. The role of nitric oxide and cGMP in platelet adhesion to vascular endothelium. Biochem Biophys Res Commun, 148:1482-9.

Rosano GM, Vitale C, Fini M. 2006. hormone replacement therapy and cardioprotection: what is good and what is bad for the cardiovascular system? Ann N Y Acad Sci, 1092:341-8.

Sader MA, Celermajer DS. Endothelial function, vascular reactivity and gender differences in the cardiovascular system. Cardiovasc Res, 53:597-604.

Samuel CS, Unemori EN, Mookerjee I, et al. 2003. Relaxin modulates cardiac fibroblast proliferation, differentiation and collagen production and reverses cardiac fibrosis in vivo. Endocrinology, 145:4125-33.

Samuel CS, Du XJ, Bathgate RAD, et al. 2006. Relaxin' the stiffened heart and arteries: the therapeutic potential for relaxin in the treatment of cardiovascular disease. Pharm Ther, 112:529-52.

Schwabe C, Büllesbach EE. 1994. Relaxin: structure, functions, promises and nonevolution. FASEB J, 8:1152-60.

Sherwood OD. 2004. Relaxin's physiological roles and other diverse actions. Endocr Rev, 25:205-34.

Siow RCM, Li FYL, Rowlands DJ et al. 2007. Cardiovascular targets for estrogens and phytoestrogens: transcriptional regulation of nitric oxide synthase and antioxidant defense genes. Free Rad Bio Med, 42:909-25.

Sluiter W, Pietersma A, Lamers JMJ, et al. 1993. Leukocyte adhesion molecules on the vascular endothelium: their role in the pathogenesis of cardiovascular disease and the mechanism underlying their expression. $J$ Cardiovasc Pharmacol, 22(Suppl 4):S37-44.

Smith GC, Pell JP, Walsh D. 2001. Pregnancy complications and maternal risk of ischaemic heart disease: A retrospective cohort study of 129,290 births. Lancet, 357:2002-6.

Stewart DR, Celniker AC, Taylor CA Jr, et al. 1990. Relaxin in the periimplantation period. J Clin Endocrinol Metab, 70: 1771-3.

St-Louis J, Massicotte G. 1985. Chronic decrease of blood pressure by rat relaxin in spontaneously hypertensive rats. Life Sci, 37:1351-7.

Sudo S, Kumagai J, Nishi S, et al. 2003. H3 Relaxin is a specific ligand for LGR7 and activates the receptor by interacting with both the ectodomain and the exoloop 2. J Biol Chem, 278:7855-62.

Taylor MJ, Clark CL. 1994. Evidence for a novel source of relaxin: atrial cardiocytes. J Endocrinol, 143:R5-8.
Tunstall PH, Kuulasmaa K, P. Amouyel P, et al. 1994. Myocardial infarction and coronary deaths in the World Health Organization MONICA Project. Registration procedures, event rates, and case-fatality rates in 38 populations from 21 countries in four continents. Circulation, 90:583-612.

Unemori EN, Amento EP. 1990. Relaxin modulates synthesis and secretion of procollagenase and collagen by human dermal fibroblasts. $J$ Biol Chem, 265:10681-5.

Unemori EN, Bauer EA, Amento EP. 1992. Relaxin alone and in conjunction with interferon- $\gamma$ decreases collagen synthesis by cultured human scleroderma fibroblasts. J Invest Dermatol, 99:337-42.

Unemori EN, Beck LS, Lee WP, et al. 1993. Human relaxin decreases collagen accumulation in vivo in two rodent models of fibrosis. $J$ Invest Dermatol, 101:280-5

Unemori EN, Pickford LB, Salles AL, et al.1996. Relaxin induces an extracellular matrix-degrading phenotype in human lung fibroblasts in vitro and inhibits lung fibrosis in a murine model in vivo. $J$ Clin Invest, 98:2739-45.

Unemori EN, Erikson ME, Rocco SE, et al. 1999. Relaxin stimulates expression on vascular endothelial growth factor in normal human endometrial cells in vitro and is associated with menometrorrhagia in women. Hum Reprod, 14:800-6.

Vanhoutte PM. 1997. Endothelial dysfunction and atherosclerosis. Eur Heart J, 18:E19-29.

Vasilenko P, Mead JP, Weidmann JE. 1986 Uterine growth-promoting effects of relaxin: A morphometric and histological analysis. Biol Reprod, 35:987-95.

Wei JY. 1992. Age and the cardiovascular system. $N$ Engl J Med, 327:1735-9.

Wenger NK, Speroff L, Packard B. 1993. Cardiovascular health and disease in women. $N$ Engl J Med, 329:247-56.

Williams EJ, Benyon RC, Trim N, et al. 2001. Relaxin inhibits effective collagen deposition by cultured hepatic stellate cells and decreases rat liver fibrosis in vivo. Gut, 49:577-83.

Wilson BC, Connell B, Saleh TM. 2006. Relaxin-induced reduction of infarct size in male rats receiving $\mathrm{MCAO}$ is dependent on nitric oxide synthesis and not estrogenic mechanisms. Neurosci Lett, 393:160-4.

Winslow JW, Shih A, Bourell JH, et al. 1992. Human seminal relaxin is a product of the same gene as human luteal relaxin. Endocrinology 130:2660-88.

Wyckoff MH, Chambliss KL, Mineo C, et al. 2001. Plasma membrane estrogen receptors are coupled to endothelial nitric oxide synthase through $\mathrm{G}_{\mathrm{i}}$. J Biol Chem, 276:27071-6.

Zdravkovic T, Genbacev O, McMaster MT, et al. 2005. The adverse effects of maternal smoking on the human placenta: a review. Placenta, 26(Suppl A):S81-6.

Zhang J, Qi YF, Geng B, et al. 2005. Effect of relaxin on myocardial ischemia injury induced by isoproterenol. Peptides, 26:1632-9.

Ziche M, Morbidelli L, Masini E, et al. 1994 Nitric oxide mediates angiogenesis in vivo and endothelial cell growth and migration in vitro promoted by substance P. J Clin Invest, 94:2036-44. 